\title{
Model-based tsunami warnings derived from observed impacts
}

\author{
S. C. R. Allen and D. J. M. Greenslade \\ Centre for Australian Weather and Climate Research, Bureau of Meteorology, Melbourne, Australia \\ Received: 6 September 2010 - Revised: 22 October 2010 - Accepted: 28 October 2010 - Published: 20 December 2010
}

\begin{abstract}
The Joint Australian Tsunami Warning Centre uses the T2 tsunami scenario database to provide forecast guidance for potential tsunami threats to the coastlines of mainland Australia and its external territories. This study describes a method for generating coastal tsunami warnings from model data obtained from the T2 scenario database. Consideration of observed coastal impacts for nine past events leads to retrospective or "ideal" warning schemes being designed. The 95th percentile values of maximum amplitude within designated coastal zones are examined and thresholds that produce the best match for the ideal schemes are selected. This empirical method is impact-based and allows the T2 scenarios to be used as a proxy for potential impacts on the coast in order to generate warnings for the Australian region.
\end{abstract}

\section{Introduction}

Following the Sumatra-Andaman Earthquake of 26 December 2004 and the resultant devastating tsunami (hereafter referred to as the Sumatra 2004 event), the Australian Government allocated AUD68.4M to the development of a comprehensive Australian Tsunami Warning System (ATWS). One of the more recent components of this warning system is the T2 tsunami scenario database, described in Greenslade et al. (2009). T2 is used in the Joint Australian Tsunami Warning Centre (JATWC) to provide forecast guidance for potential tsunami threats to the coastlines of mainland Australia and its external territories.

The $\mathrm{T} 2$ database consists of pre-computed simulations (or "scenarios") of tsunami propagation in water deeper than $20 \mathrm{~m}$, using the Method Of Splitting Tsunamis (MOST) model (Titov and Synolakis, 1998). In an event, the closest

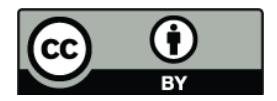

Correspondence to: S. C. R. Allen (stewart.allen@bom.gov.au) scenario is selected and scaled to match the event magnitude (Greenslade et al., 2009; Simanjuntak and Greenslade, 2010). Ideally, these scenarios could be used to generate boundary conditions for high-resolution coastal inundation modelling for use in forecasting coastal tsunami impacts. However, the bathymetry data required to accurately model inundation in this manner does not exist for the entire Australian coastline. Therefore, in order to generate warnings for the Australian region, the T2 scenarios are used as a proxy for potential impacts on the coast.

The basis for the method through which this is done has been described in Allen and Greenslade (2008; hereafter referred to as AG08). This was based on T1 (Greenslade et al., 2007), which is an earlier, more primitive version of the tsunami scenario database. Furthermore the the technique of AG08 also had a number of limitations. The development and implementation of $\mathrm{T} 2$ provides the opportunity to reassess the method and incorporate some enhancements.

In this paper, the method of AG08 is briefly summarised in Sect. 2, and the reasons for redoing the technique are explained in more detail. Section 3 contains details of the technique by which the method is designed, based on observed impacts from past tsunami events. Section 4 examines the results of applying the technique designed in Sect. 3 to model simulations for each past tsunami event. Section 5 considers the appropriateness of the threshold chosen for a "land threat" warning. Lastly, Sect. 6 discusses some of the findings and limitations of the study.

\section{Previous work}

The method of AG08 mapped the field of T1 maximum amplitude, $\left|H_{\max }\right|$, to a number of coastal zones (e.g. see Fig. 1). Warnings were produced when the maximum value of $\left|H_{\max }\right|$ in a zone exceeded set thresholds. These thresholds were initially chosen on the basis of theoretical arguments (i.e. Green's law) and previous research (Whitmore, 2003)

Published by Copernicus Publications on behalf of the European Geosciences Union. 


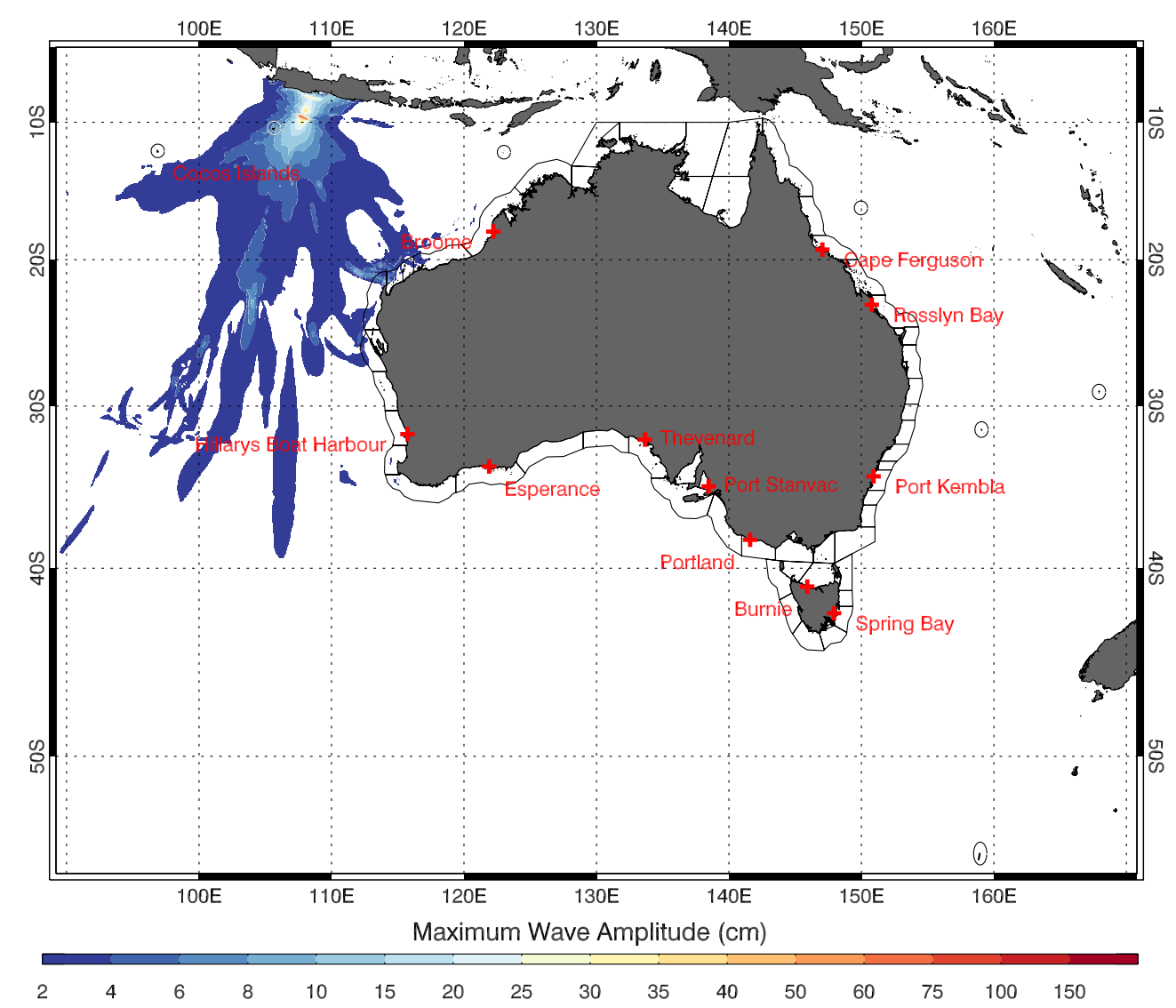

Fig. 1. An example of a map of $H_{\max }$ from a T2 scenario. Also shown are the coastal zones used in this study. The coastal zones not bordering the Australian mainland or Tasmania are shown larger than scale for clarity. The locations of the tide gauges used in this study to design the retrospective warning schemes are also indicated.

that had suggested specific tide gauge amplitudes for "dangerous" tsunamis. The thresholds were tuned and verified by examining the overall warnings schemes for past tsunami events.

The simplest approach to deriving tsunami warnings from the T2 scenario database would be to apply the previously derived thresholds and technique for $\mathrm{T} 1$ to the $\mathrm{T} 2$ scenario database. However, for a number of reasons, this is not appropriate. These reasons are briefly noted below and some are discussed in more detail later in this study:

- The maximum amplitude field output from $\mathrm{T} 1$ is $\left|H_{\max }\right|$, i.e. the maximum of the absolute value of the amplitude. T2 uses only the positive $H_{\max }$ values. This change was made in order to be consistent with other international databases (e.g. SIFT; Gica et al., 2008).

- There have been a number of changes made to the scenarios in going from $\mathrm{T} 1$ to $\mathrm{T} 2$, such as the use of a 24-h model run (as opposed to 10 hours) and enhanced subduction zone representations. These have changed maximum amplitude values quite significantly in some cases.
- The use of Green's Law to translate offshore values of $\left|H_{\max }\right|$ from $\mathrm{T} 1$ or $H_{\max }$ from $\mathrm{T} 2$ to a value at an approximate tide gauge depth, or at the beach is not valid given the many assumptions made in the derivation of Green's Law.

- In retrospect, it appears that the thresholds implemented for $\mathrm{T} 1$ result in warnings that are excessive in number and severity. For example, the $\mathrm{T} 1$ technique for the Sumatra 2004 event results in "land threats" for a large portion of the WA coast. Although this was deemed appropriate when the thresholds were initially developed, further experience with operational tsunami warnings within the JATWC has indicated that "marine threats" are more appropriate in this case (the meanings of these threats are defined explicitly in Sect. 3).

- The individual maximum $\left|H_{\max }\right|$ (or $H_{\max }$ ) value is often an outlier compared to other values in a given coastal zone.

In this study, a new strategy is developed. Consideration of observed coastal impacts for nine past events (listed in Table 1) leads to retrospective or "ideal" warning schemes 
Table 1. Tsunami events used to evaluate coastal warning thresholds.

\begin{tabular}{|c|c|c|c|c|}
\hline Event Name & Time & $\begin{array}{l}\text { Epicentre } \\
\text { Longitude }\end{array}$ & $\begin{array}{l}\text { Epicentre } \\
\text { Latitude }\end{array}$ & $M_{\mathrm{W}}$ \\
\hline Chile 1960 & $\begin{array}{l}22 \text { May } 1960 \\
\text { 19:11 UTC }\end{array}$ & $74^{\circ} 30^{\prime} \mathrm{W}$ & $39^{\circ} 30^{\prime} \mathrm{S}$ & 9.5 \\
\hline Sumatra 2004 & $\begin{array}{l}26 \text { Dec } 2004 \\
\text { 00:59 UTC }\end{array}$ & $95^{\circ} 74^{\prime} \mathrm{E}$ & $3^{\circ} 18^{\prime} \mathrm{N}$ & 9.1 \\
\hline Sumatra 2005 & $\begin{array}{l}28 \text { Mar } 2005 \\
\text { 16:10 UTC }\end{array}$ & $97^{\circ} 01^{\prime} \mathrm{E}$ & $2^{\circ} 04^{\prime} \mathrm{N}$ & 8.7 \\
\hline Tonga 2006 & $\begin{array}{l}3 \text { May } 2006 \\
\text { 15:27 UTC }\end{array}$ & $174^{\circ} 13^{\prime} \mathrm{W}$ & $20^{\circ} 06^{\prime} \mathrm{S}$ & 7.9 \\
\hline Java 2006 & $\begin{array}{l}17 \text { Jul } 2006 \\
08: 19 \text { UTC }\end{array}$ & $107^{\circ} 18^{\prime} \mathrm{E}$ & $9^{\circ} 18^{\prime} \mathrm{S}$ & 7.7 \\
\hline Solomons 2007 & $\begin{array}{l}1 \text { Apr } 2007 \\
\text { 20:40 UTC }\end{array}$ & $156^{\circ} 59^{\prime} \mathrm{E}$ & $8^{\circ} 29^{\prime} \mathrm{S}$ & 8.1 \\
\hline Sumatra 2007 & $\begin{array}{l}12 \text { Sep } 2007 \\
11: 10 \text { UTC }\end{array}$ & $101^{\circ} 23^{\prime} \mathrm{E}$ & $4^{\circ} 31^{\prime} \mathrm{S}$ & 8.4 \\
\hline Puysegur 2007 & $\begin{array}{l}30 \text { Sep } 2007 \\
05: 23 \text { UTC }\end{array}$ & $163^{\circ} 52^{\prime} \mathrm{E}$ & $49^{\circ} 18^{\prime} \mathrm{S}$ & 7.4 \\
\hline Puysegur 2009 & $\begin{array}{l}15 \text { Jul } 2009 \\
09: 22 \text { UTC }\end{array}$ & $166^{\circ} 35^{\prime} \mathrm{E}$ & $45^{\circ} 45^{\prime} \mathrm{S}$ & 7.8 \\
\hline
\end{tabular}

being designed. These ideal schemes reflect the actual impacts of the tsunamis considered within the coastal zones. The T2 $H_{\max }$ values within each coastal zone are then examined and the thresholds that produce the best match for the ideal schemes can be selected. In this way, a major difference to the technique of AG08 is that observed impacts from previous events are used to define the warnings method, rather than verify it.

The use of Green's Law is avoided in this study, given the number of assumptions that are needed for it to be strictly valid. It assumes a long, straight coastline, a moderate and constant bottom gradient and wave amplitudes that are much smaller than the depth of the fluid (Mei et al., 2005). In near shore environments with complex bathymetry, nonlinear effects become important and Green's Law breaks down. Although it serves as a simple, useful and widely used approximation, its use is avoided here where possible for the reasons outlined above.

The set of coastal zones used with T2 (Fig. 1) is almost identical to that used in AG08, with only some slight modifications to accommodate some un-related Bureau of Meteorology requirements. These coastal zones follow sections of coastline on the order of tens to hundreds of kilometres and extend from the coastline approximately 60 nautical miles. They were chosen on the basis that they are already used for marine warning purposes and so forecasters, emergency managers and the public are familiar with them. No factors relating to tsunamis were taken into account during their design.
The study of AG08 assigned separate thresholds to the socalled "external territories", arguing that not only were those zones smaller than the continental zones, but also that they were substantially different morphologically. This resulted in different tsunami dynamics and a different statistical distribution of the $\mathrm{T} 1\left|H_{\max }\right|$ values within these external zones. In this study, the external territories are not treated separately for reasons of operational simplicity within the JATWC.

As stated above, the method of AG08 compared the largest value of $\left|H_{\max }\right|$ to pre-determined threshold values and applied a warning if the thresholds were exceeded. Figure 2 shows some examples of ranked values of $H_{\max }$ for several coastal zones. By plotting ranked values of $H_{\max }$ for each zone, it is evident that the largest value is very much an outlier. The data in Fig. 2, although for different events and locations, are largely typical of all events for the coastal zones. The 95th percentile value is indicated on these figures by the horizontal bar. The use of a percentile value as the threshold, instead of the maximum value, effectively means that a number of high $H_{\max }$ values for each zone are being used to predict the impact, rather than just a single value, providing a more robust method. The choice of which percentile to use is somewhat arbitrary. The 90th percentile value was also investigated as a potential threshold trigger, but this did not produce results that were substantially different to the 95 th percentile.

\section{Warnings design}

In this study, tsunami warnings are categorised into three levels of threat. This is the technique that has been adopted operationally by the JATWC and was used in AG08. The three levels are:

\section{No threat.}

2. Marine threat, indicating potentially dangerous waves and strong ocean currents in the marine environment.

3. Land threat, indicating major land inundation of lowlying coastal areas, dangerous waves and strong ocean currents.

In order to derive appropriate thresholds, nine past tsunami events have been considered as a means by which warnings schemes can be designed. These events are listed in Table 1. The nearest $\mathrm{T} 2$ scenario listed in the table for each event was found by choosing the scenario whose initial conditions best match up with finite fault model solutions for each event. The finite fault model solutions were obtained from the USGS (2010a) for all of the events examined here except for Chile 1960 and Puysegur 2007. Rupture details for Chile 1960 were taken from Plafker (1972) while details for Puysegur 2007 were obtained from Bathgate et al. (2008). 

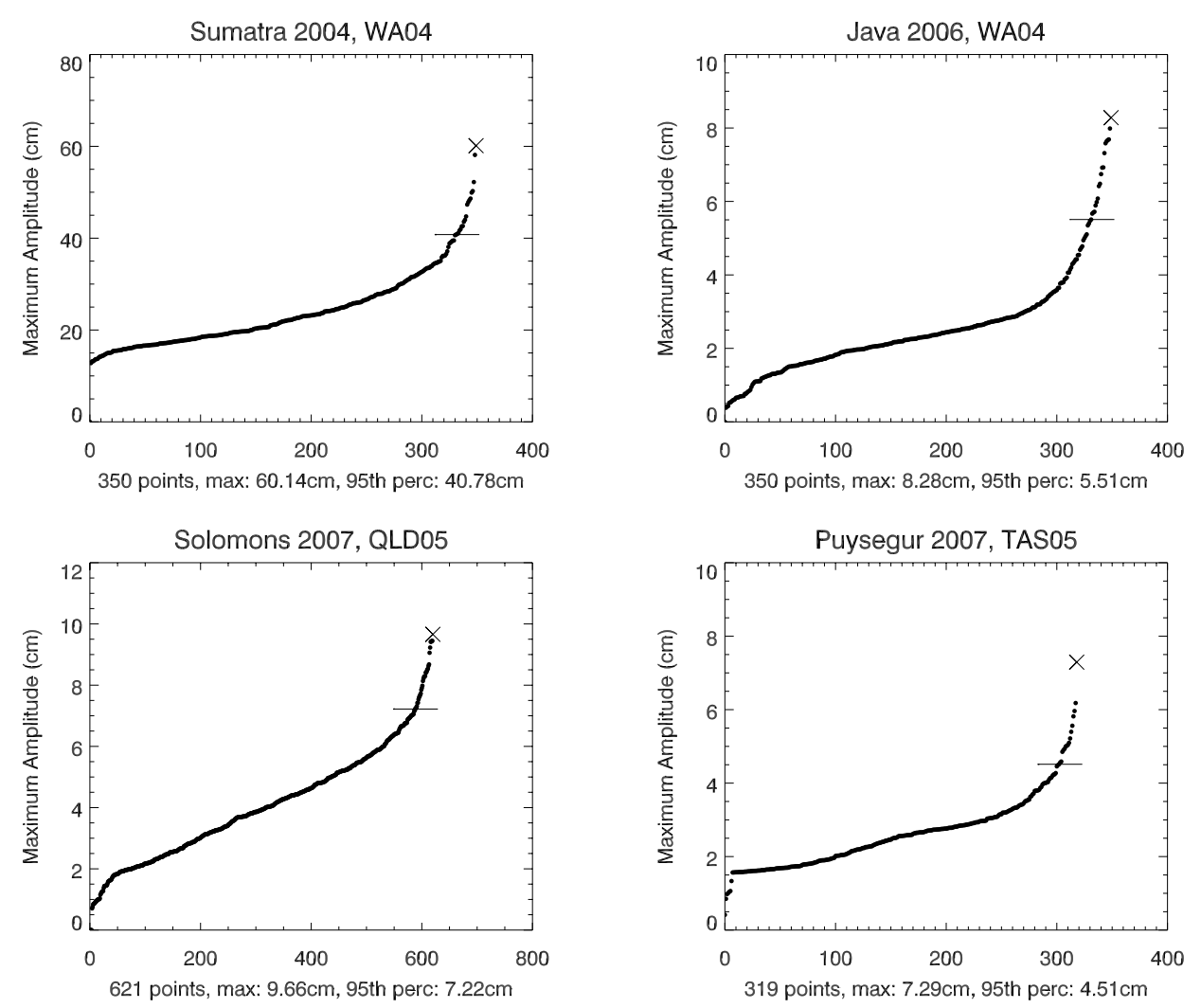

Fig. 2. Ranked values of $H_{\max }$ for several coastal zones surrounding the Australian mainland. The maximum value in each zone is marked with a cross and the 95 th percentile value is marked with a horizontal bar.

As documented in Greenslade et al. (2009), the T2 database only consists of events computed at magnitudes $M_{\mathrm{w}}=7.5,8.0,8.5$, and 9.0. Therefore, the field of $H_{\max }$ from the nearest scenario is scaled (if necessary) to the event magnitude using the method described in Greenslade et al. (2009). This method linearly scales scenarios with respect to slip, while holding other parameters constant.

Reports of impacts used to design the warnings are drawn from a number of sources. These provide an indication of whether a tsunami warning was needed for each coastal zone and what level of warning was required. One source of information is media reports of effects on individuals or property, strange and irregular currents or tides and coastal inundation. A source of quantitative data is that provided by the network of coastal tide gauges. It is not straightforward to deduce tsunami impacts (and therefore the required level of warning) from tide gauge amplitudes. Whitmore (2003) had suggested that tsunami amplitudes above $50 \mathrm{~cm}$ at a tide gauge produced potentially dangerous tsunamis, and this value provides a potential threshold for issuing a marine threat. However, the use of this value in AG08 to derive thresholds resulted in a level of warning that was deemed too high and is in need of modification, as discussed in Sect. 2.

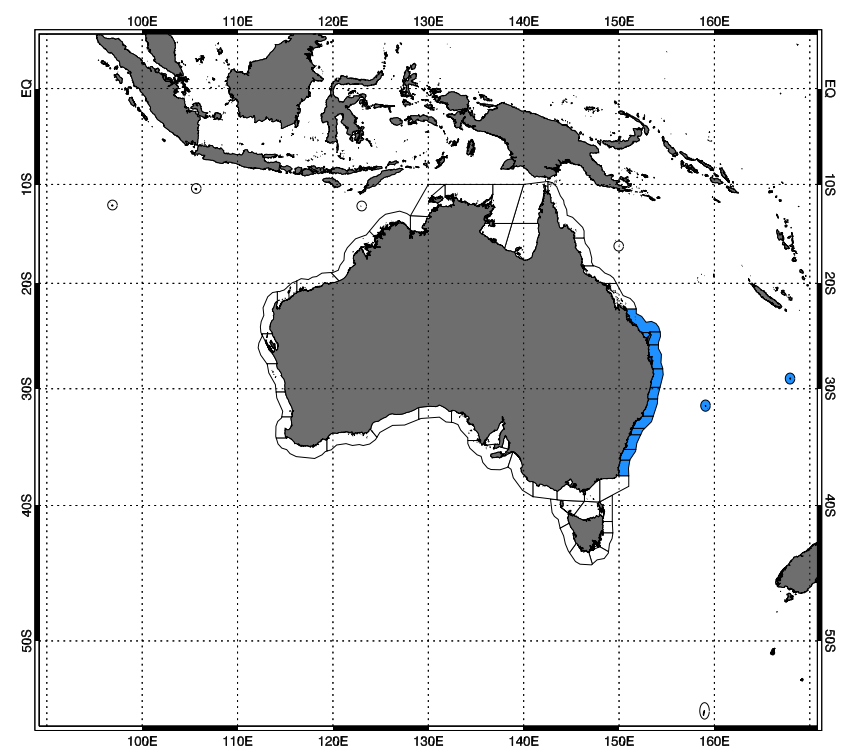

Fig. 3. Desired warning scheme for the Chile 1960 event. Coastal zones assigned a marine threat are shaded in blue. 


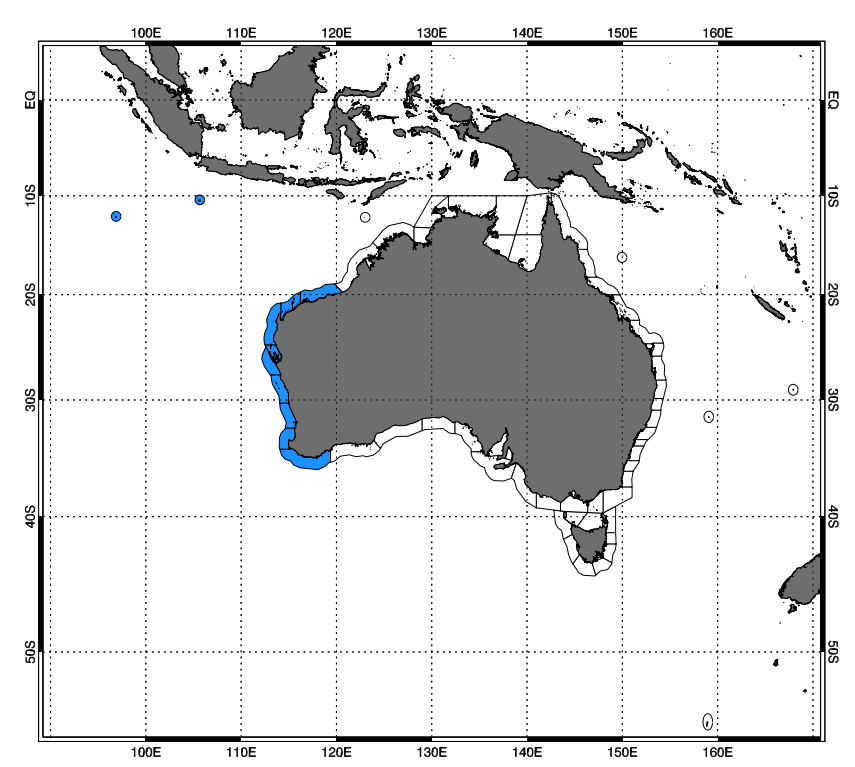

Fig. 4. Desired warning scheme for the Sumatra 2004 event. Coastal zones assigned a marine threat are shaded in blue.

Over the first few years of the operation of the JATWC and experience with a number of tsunami events, the JATWC has agreed upon a set of tide gauge amplitudes that are used to confirm whether or not the issuing of a tsunami warning was justified (NMOC, 2010). These are approximate values only and have not been derived quantitatively but solely through experience with observations and events. For a justified no threat warning, tide gauge amplitude values should have been less than $40 \mathrm{~cm}$; for a marine threat, amplitudes should be between $40 \mathrm{~cm}$ and $100 \mathrm{~cm}$; and for a land threat, amplitudes should exceed $100 \mathrm{~cm}$. The set of tide gauges used in this study consists of most of the instruments in the Bureau of Meteorology's baseline sea level monitoring project (Bureau of Meteorology, 2010). Data from 12 gauges were available and the location of each gauge is marked in Fig 1.

\subsection{Events and desired warning schemes}

\subsubsection{Chile 1960}

This event had the largest magnitude of any recorded earthquake and produced a large ocean-wide tsunami. Tsunami related deaths occurred close to the source in Chile and remotely in Hawaii and Japan.

Dominey-Howes (2007) notes that the main regions of impact on Astralian coastlines for this event were New South Wales and Queensland with smaller but insignificant impacts from Victoria to southern Western Australia and Tasmania. The desired warning scheme in Fig. 3 reflects these impacts with marine warnings in these areas.

\subsubsection{Sumatra 2004}

For this event, there were numerous reported impacts on the West Australian coastline, including the sinking of a moored vessel, people rescued after being washed out to sea, and inundation of some buildings (e.g. Northwest Telegraph, 2005).

Tidal behaviour at many sites was irregular and rapid (Rabinovich and Thomson, 2007). The gauges marked in Fig. 1 recorded amplitudes either between $40 \mathrm{~cm}$ and $100 \mathrm{~cm}$, or below $40 \mathrm{~cm}$, with the largest observation of $60 \mathrm{~cm}$ recorded at Hillarys in Western Australia.

The ideal, designed scheme for this event is shown in Fig. 4 and shows marine warnings for much of the Western Australian coastline, as well as the Cocos Islands and Christmas Island. This scheme encloses the zones in which there were reported impacts, as well as the locations where tide gauge amplitudes were recorded that exceeded the JATWC thresholds (with one exception at the Cocos Islands).

The regions outside where marine threats would be issued did not experience any significant impacts (or, at least, are not known to have). Examination of residual sea level at tide gauges along southern and south-eastern Australia reveals mostly small disturbances that were below the JATWC threshold. The only exception was at Portland, Victoria where relatively large disturbances were observed.

The tide gauge at the Cocos Islands is located within a zone with a marine warning for the desired scheme, however the observed amplitude from this gauge during this event was $35 \mathrm{~cm}$ and so does not exceed the thresholds used by the JATWC's method for assessing tide gauge observations. It has been observed over several tsunami events that this gauge consistently displays tsunami observations that are smaller than other gauges in the vicinity. Allen and Greenslade (2009) suggest that this may be because this gauge is largely free of amplification effects from local bathymetry, in comparison with most other gauges in the Australian tide gauge network.

In a similar way, but in contrast to the Cocos Islands gauge, Allen and Greenslade (2009) also suggested the tide gauge situated at Portland strongly amplified tsunamis and other sources of sea level variability. This accounts for the relatively large tide gauge amplitudes of $45 \mathrm{~cm}$ seen during this event at this location, despite no other reported nearby impacts. In other words, the tsunami amplitude at Portland is not representative of impacts throughout the coastal zone and so a warning for that coastal zone is not required.

\subsubsection{Sumatra 2005}

Despite being a very large earthquake, this event produced only a local (but damaging) tsunami (USGS, 2010b). No impacts were observed at the Australian coastline and tide gauges recorded only small disturbances. The desired warning scheme in Fig. 5 reflects this. 


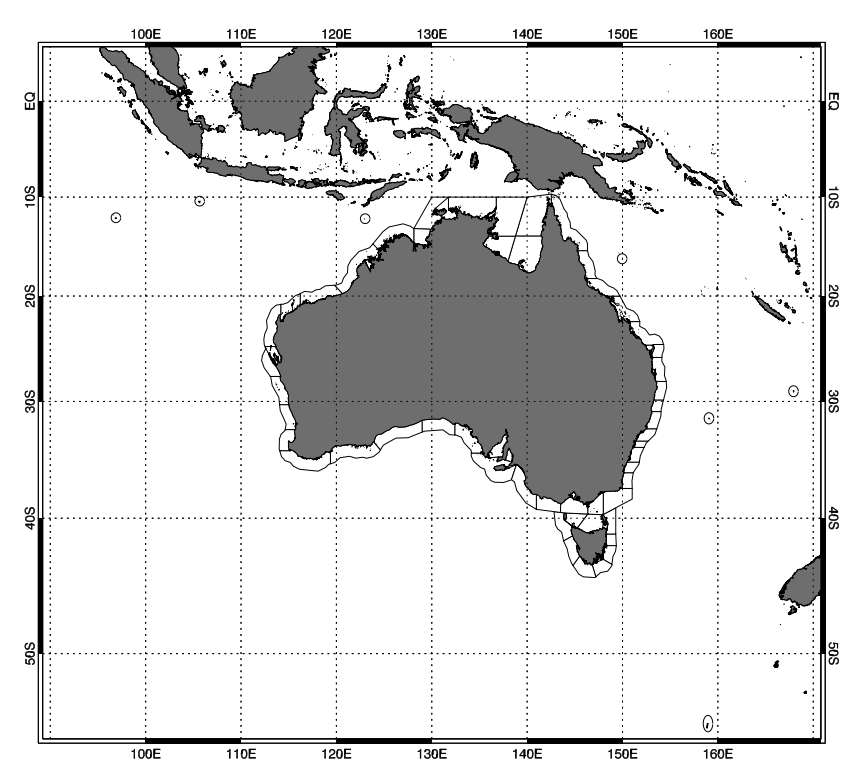

Fig. 5. Desired warning scheme for the Sumatra 2005 event. No marine or land threats were assigned to any coastal zone.

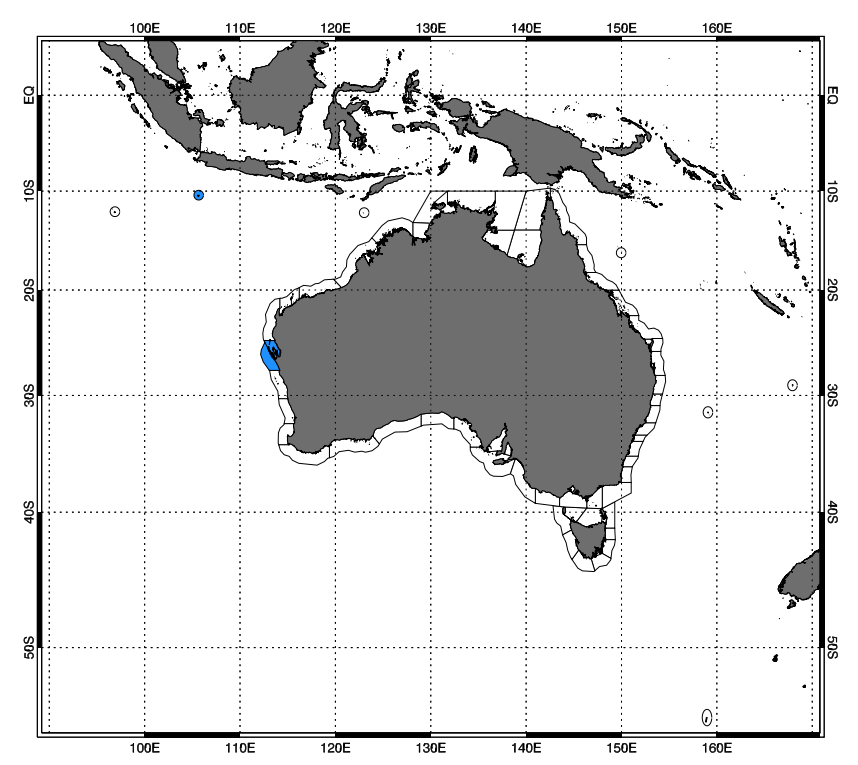

Fig. 6. Desired warning scheme for the Java 2006 event. Coastal zones assigned a marine threat are shaded in blue.

\subsubsection{Tonga 2006}

This event has been considered in detail by several studies, such as Tang et al. (2008), Greenslade and Titov (2009) and, in the specific context of T2, Greenslade et al. (2010). This event produced no impacts on the Australian coastline or external territories and the desired warning scheme consists of no threats in any coastal zone (not shown).

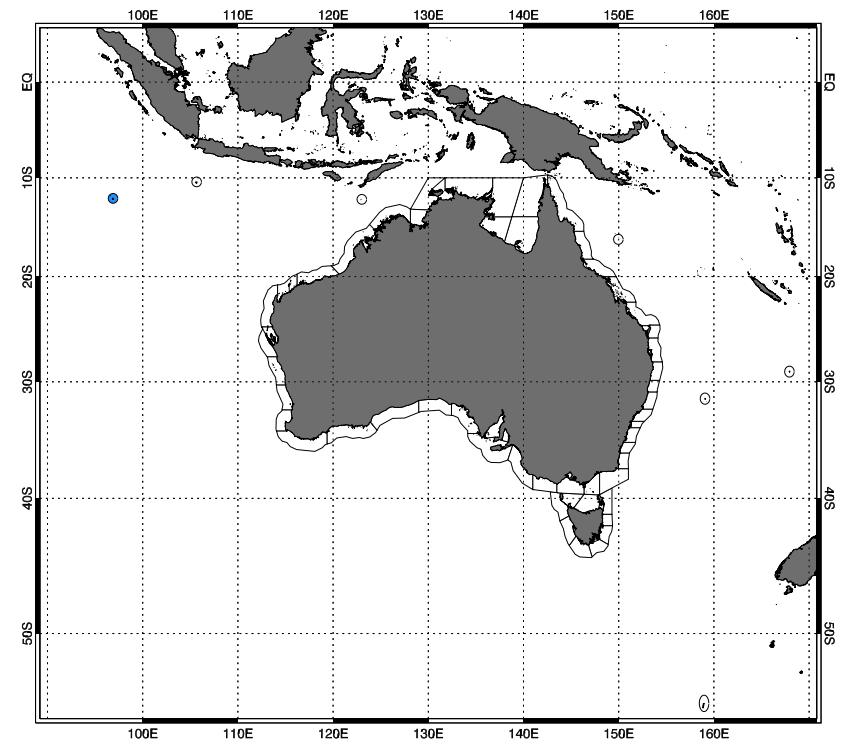

Fig. 7. Desired warning scheme for the Sumatra 2007 event. Coastal zones assigned a marine threat are shaded in blue. The derived $\mathrm{T} 2$ warnings for this event are not shown but are discussed in the text.

\subsubsection{Java 2006}

The Java 2006 event, despite the relatively small magnitude of the earthquake, produced a locally damaging tsunami that resulted in the loss of hundreds of lives in Indonesia. The earthquake has been categorised as a "slow" or "tsunami" earthquake (Ammon et al., 2006). The tsunami was also observed at Steep Point, on the central Western Australia coast, where there was significant localised inundation (Prendergast, 2006).

Figure 6 shows the desired warnings for the event, with a marine warning placed for Christmas Island, given its proximity to the earthquake, and the zone containing Steep Point. Tide gauge amplitudes for locations on the West Australian coastline were below the JATWC thresholds. However, the gauge located at Christmas Island suggested a marine threat was necessary there, as it recorded a wave amplitude of $50 \mathrm{~cm}$.

\subsubsection{Solomons 2007}

This event produced a damaging tsunami close to the source (The Age, 2007), but only a minor (i.e. detectable) tsunami on the Australian coastline. Although AG08 suggested that most of the coastal zones along the Queensland coast required marine warnings, in retrospect, it is considered that these warnings were unwarranted. Tide gauge observations on the eastern coastline of Australia showed only small to moderate disturbances and there were no reports of damaging impacts. Therefore, the only desired warning for this event (not shown) is a marine warning at Norfolk Island. 


\subsubsection{Sumatra 2007}

The Sumatra 2007 event was smaller in magnitude than the previous two Sumatra events considered, but the rupture was located slightly closer to the Australian coastline.

As seen in Fig. 7, the desired warnings scheme consists solely of a marine warning at the Cocos Islands. Like Christmas Island for the Java 2006 event, this is due to the close proximity of the Cocos Islands to the earthquake. There were no documented impacts on the Australian coastline. Tide gauge records for both the Cocos Islands and Christmas Island showed only small disturbances during this event.

\subsubsection{Puysegur 2007}

The Puysegur 2007 event, at $M_{\mathrm{W}}=7.4$, is the smallest of the events examined in this study. However, it occurred on the fault line of most interest to Australia, since it is the closest to several large population centres.

This event produced a small tsunami that was detected by a tsunameter positioned close to the source in the Tasman Sea and on tide gauges in south-eastern Australia. However, there were no impacts from this tsunami and the desired warnings scheme has no coastal zones with any warnings (not shown).

\subsubsection{Puysegur 2009}

This tsunami was detected on Tasman Sea tsunameters and coastal tide gauges (Uslu et al., 2010), however no significant impacts were observed and so the desired warning scheme consists of no threats in any coastal zone (not shown). Note that when this event occurred, the operational T1 database and warning technique produced marine threats for the southeast coast of Australia (from New South Wales to Tasmania), Norfolk Island and a land threat for Lord Howe Island. In hindsight, these warnings were deemed excessive.

\subsection{Selection of thresholds based on desired warning schemes}

For each of the events described in Sect. 3.1, the closest T2 scenario was selected (see Table 1) and the 95th percentile value of $H_{\max }$ within each coastal zone was found. Figure 8 shows a plot of these values for each coastal zone and each event (9 events in 72 coastal zones provides 648 points in total). Based on the desired warning schemes described in Sect. 3.1, the blue data points in Fig. 8 depict the coastal zones with desired marine warnings. It can be seen that, In general, the $H_{\max }$ values for zones where warnings are desired are higher than those in zones where warnings are not desired (i.e. a "no threat" warning), which is an encouraging sign. However there is no distinct threshold that separates the two sets of values. In order to optimise the replication of the desired warnings, the recommended thresholds are

- No threat: $H_{\max }<20 \mathrm{~cm}$.
- Marine threat: $20 \mathrm{~cm} \leq H_{\max }<55 \mathrm{~cm}$.

- Land threat: $H_{\max } \geq 55 \mathrm{~cm}$.

These thresholds are marked on Fig. 8 by the dashed, horizontal lines.

It is important to note that in contrast to AG08, none of the nine past events listed in Table 1 was deemed to have produced significant or widespread inundation of land areas requiring the issuance of a Land Threat warning. This means that this method provides no guidance about where to set the threshold for a land threat. Therefore, the land threat threshold was set just above the highest marine warning values in Fig. 8. This is because there is currently no evidence to suggest that an event with amplitude above this threshold would not need a land warning. This is a conservative approach and the choice of this particular threshold will be discussed further in Sect. 5 .

\section{Results}

There are a number of coastal zones evident in Fig. 8 that ideally would have marine warnings but fall below the chosen threshold, and conversely, a number that fall above the threshold but do not require warning. This means that the desired warning schemes will not be reproduced exactly by this method. In this section, we evaluate these results by re-examining each event and assessing the derived warnings schemes that result from using the recommended threshold values listed in Sect. 3.2.

The Tonga 2006 and Puysegur 2007 events were deemed to have not required any warnings and the derived warning schemes also reflect this. Therefore, there is no discussion of these events below.

\subsection{Chile 1960}

The derived warning scheme, shown in Fig. 9, matches the desired scheme (Fig. 3) closely, except that it does not capture the marine threat suggested for Lord Howe Island or the small, enclosed coastal zone encompassing Hervey Bay.

\subsection{Sumatra 2004}

Applying the warnings method to the Sumatra 2004 event, Fig. 10 shows that marine threats would be issued for the Cocos Islands and much of the Western Australia coastline. This result matches the desired scheme depicted in Fig. 4 well, with one extra zone on the West Australian coast being issued a warning where one was not desired, but no warning being issued for Christmas Island. 


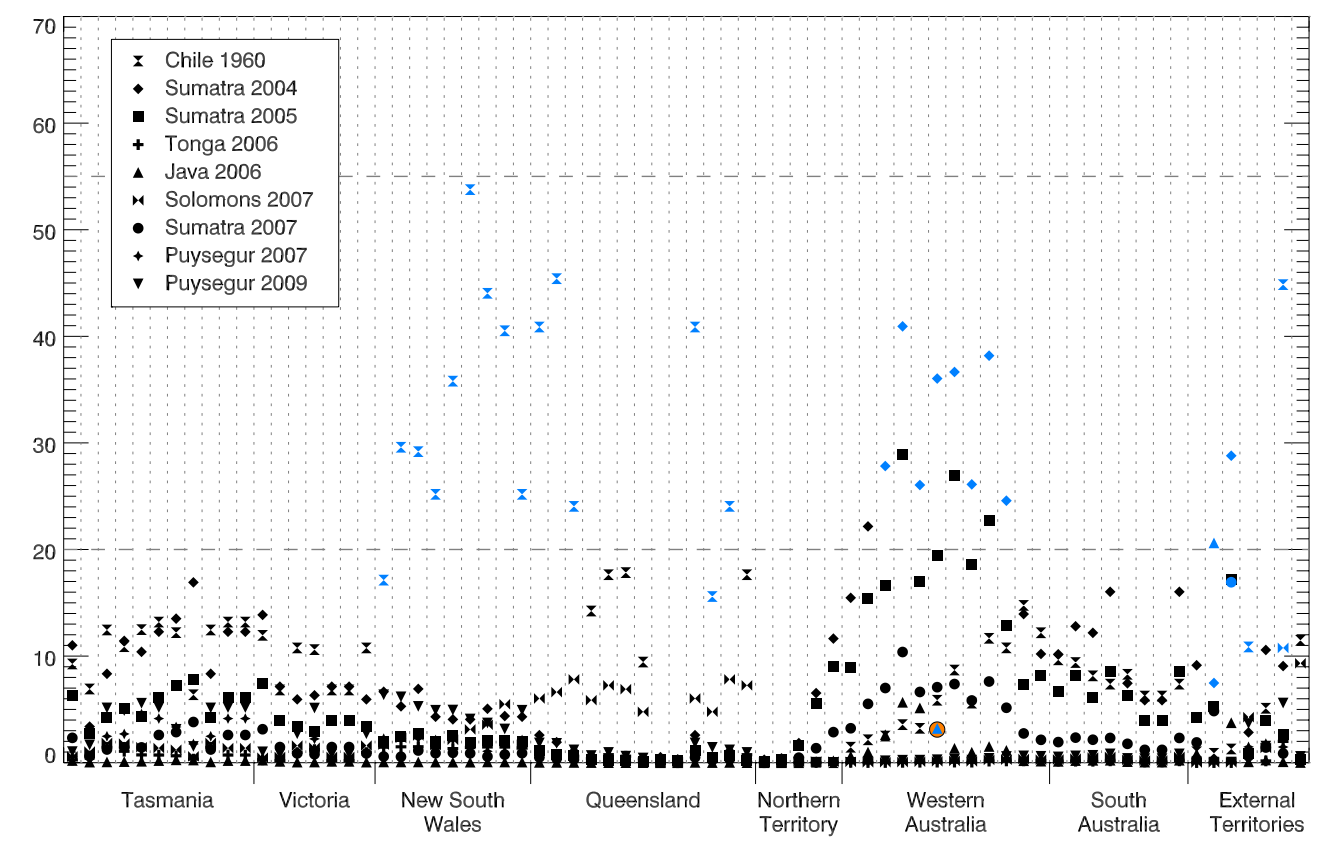

Fig. 8. 95th percentile values of $H_{\max }$ in each of the coastal polygons for all events considered in this study. External territories are towards the right-hand side of the figure. For each event, marine warnings were desired in the regions marked by blue symbols. The orange symbol in the lower right is described in Sect. 4.4. The thresholds from Sect. 3.2 are marked by the dashed lines.

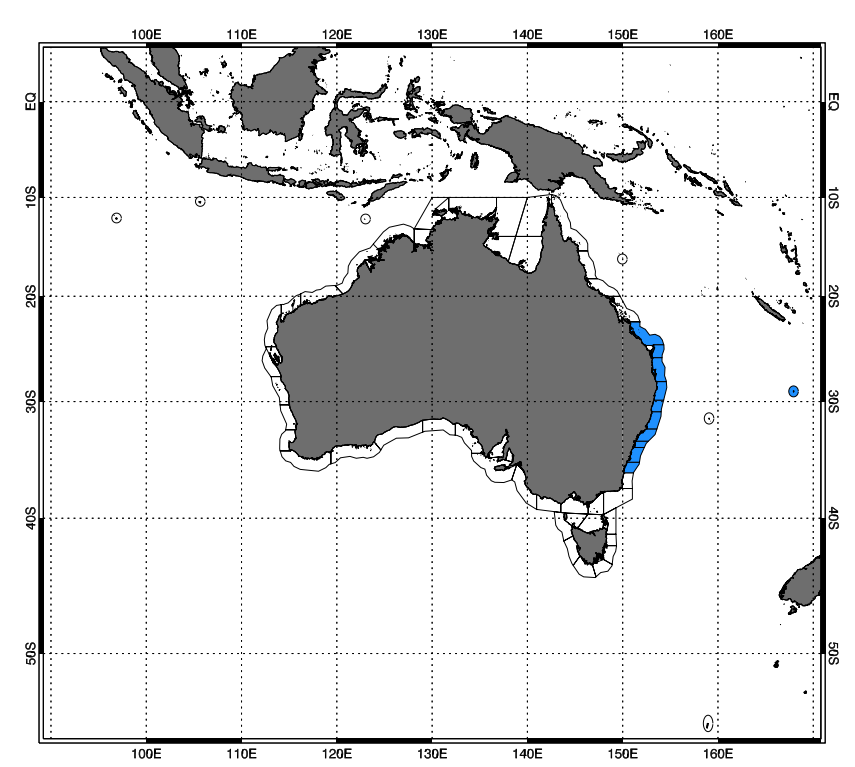

Fig. 9. Derived T2 warnings for the Chile 1960 event based on the thresholds Coastal zones assigned a marine threat are shaded in blue.

\subsection{Sumatra 2005}

As described above, this event represents an interesting example. Although the desired warning scheme depicted in Fig. 5 shows no coastal zones with a warning, the resulting warning scheme provided by this method, shown

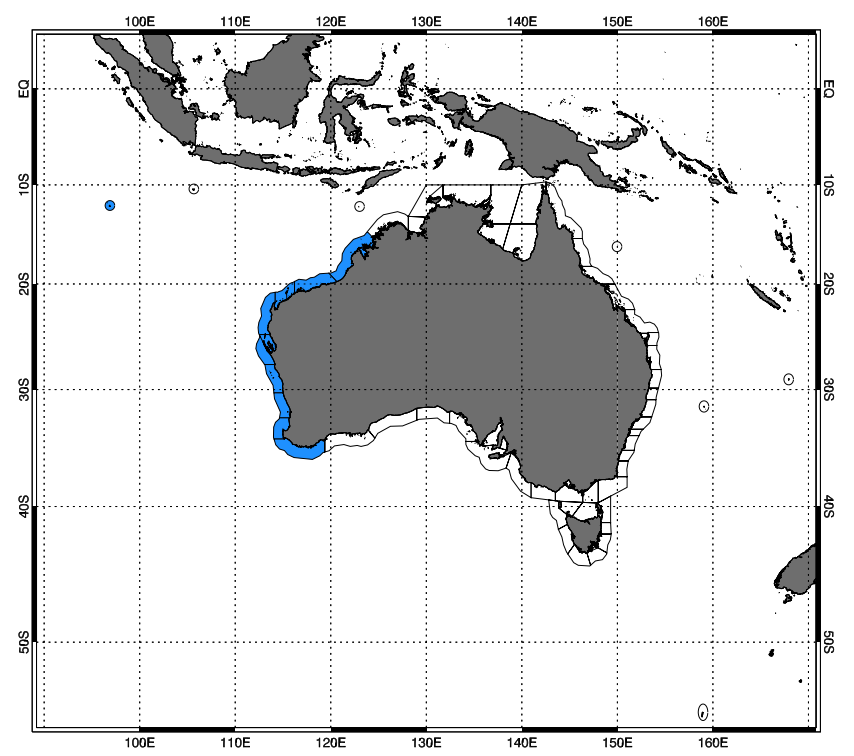

Fig. 10. Derived T2 warnings for the Sumatra 2004 event based on the thresholds in Sect. 3.2. Coastal zones assigned a marine threat are shaded in blue.

in Fig. 11, contains marine warnings for three zones in Western Australia. Furthermore, a forecaster faced with the warning scheme shown in Fig. 11 would most likely issue warnings for the two intermediate zones on the West Australian coastline, in order to provide a smooth and 


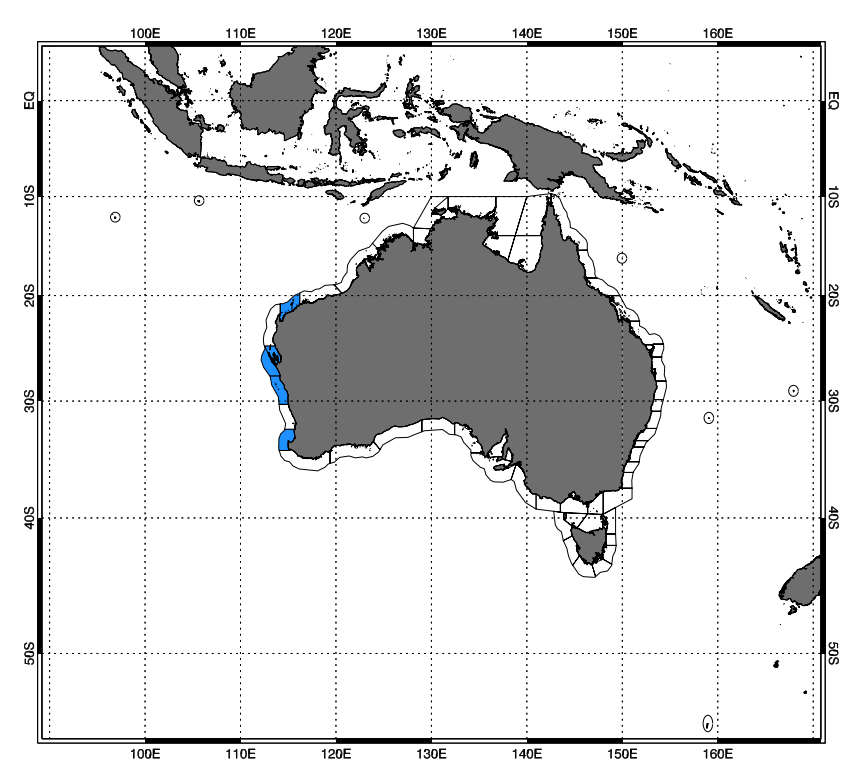

Fig. 11. Derived T2 warnings for the Sumatra 2005 event based on the thresholds in Sect. 3.2. Coastal zones assigned a marine threat are shaded in blue.

consistent warning scheme. This result arguably illustrates a limitation in a forecast system that is based on a static scenario database, rather than limitations in the warning method. T2 scenarios must use somewhat idealised initial conditions for the sea surface displacement that may not match the actual earthquake. This underscores the need for extensive sea level observations and a real-time data assimilation technique. Such a technique could be used to improve forecasts of tsunami propagation and is an area of active research.

\subsection{Java 2006}

Figure 12 shows the derived warnings for the Java 2006 event with Christmas Island as the only zone receiving a warning. The marine threat that arises here is undoubtedly due to the island's close proximity to the earthquake. There are no other zones with threats, which is unsurprising given the relatively small earthquake.

Although a marine warning is desired at Steep Point where inundation was observed, this is not reflected in the derived T2 warnings. The 95th percentile value of $H_{\max }$ for this event in this coastal zone is indicated on Fig. 8 as a blue triangle surrounded by an orange circle. It can be seen that if the thresholds are set so that this zone has a marine warning, then there would be a large number of other coastal zones for this event and others where marine warnings would be issued where they are not desired. It is highly likely that the impact seen at Steep Point is due to local amplification of the tsunami waves, which cannot be represented by the T2 model output.

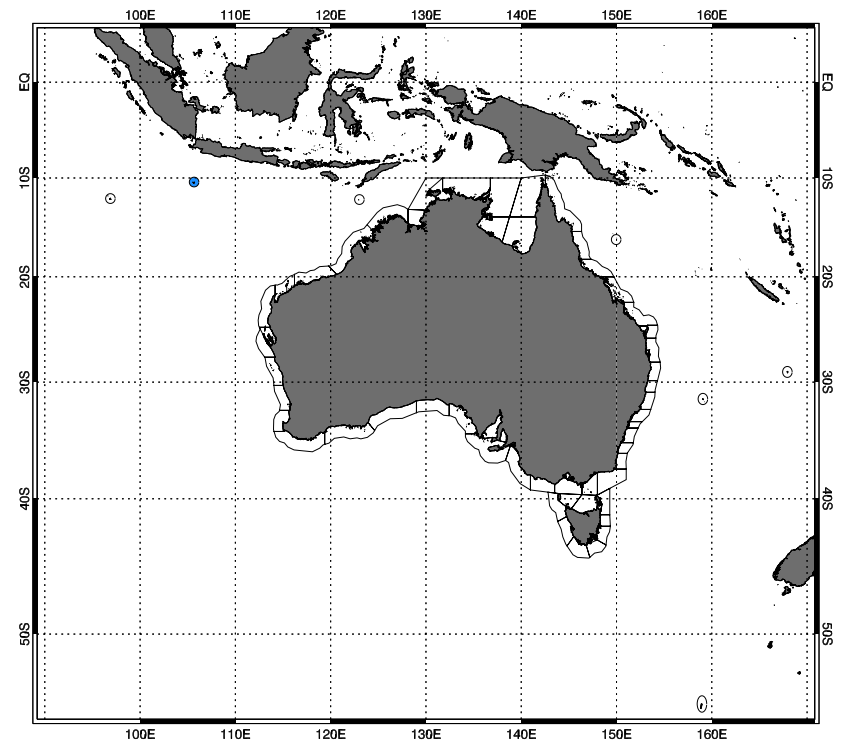

Fig. 12. Derived T2 warnings for the Java 2006 event based on the thresholds in Sect. 3.2. Coastal zones assigned a marine threat are shaded in blue.

It is not surprising that $\mathrm{T} 2$ was unable to capture the impacts at Steep Point of this localised but significant event, and if a similar earthquake like this were to occur, a warning might be manually issued for this zone given the experience of this event. However it should be noted that all operational tsunami warnings issued by the JATWC already include a caveat noting that localised impacts may occur. The impacts of this case provide a strong basis for the inclusion of this caveat. This case also provides a strong argument for the development of a warning technique based on local inundation models that might forecast this type of impact more accurately.

\subsection{Solomons 2007}

The desired warning scheme for this event, as described in Sect. 3.1.6, consists only of a single marine threat for Norfolk Island. The derived $\mathrm{T} 2$ warnings result in no warnings for any coastal region (not shown). Norfolk Island did contain the largest T2 95th percentile $H_{\max }$ value $(10.8 \mathrm{~cm})$ for the Solomons 2007 event in Fig. 8, but it was still well below the recommended marine warning threshold.

\subsection{Sumatra 2007}

The desired warning scheme for this threat was shown in Fig. 7 and consisted only of a marine threat for the Cocos Islands. However the derived scheme (not shown) has no warnings for any coastal zone. Although the Cocos Islands did contain the largest 95th percentile $H_{\max }$ value $(16.7 \mathrm{~cm})$ for the Sumatra 2007 event in Fig. 8, it was below the recommended marine warning threshold. 


\subsection{Puysegur 2009}

Section 3.1.9 stated that no significant impacts were observed in any coastal zone following this event. The derived warning scheme (not shown) also produces no warnings for either the mainland or external territories, in agreement with this observation.

It is perhaps worth noting here that these warnings are based on the closest $\mathrm{T} 2$ scenario that has been scaled down to the appropriate magnitude, as listed in Table 1 . Figure 13 shows a comparison of the time series of sea level fluctuations from the closest $\mathrm{T} 2$ scenario with observations from tsunameters 55015 and 55013, which are located in the Tasman Sea. The raw tsunameter observations have been filtered using a Kaiser-Bessel band-pass filter with 300 weights and a window bound by cut-off periods of $180 \mathrm{~min}$ and $5 \mathrm{~min}$. The filter is required in order to remove the tidal signal and other low-frequency variability, as well as any high-frequency seismic waves that were generated by the earthquake but may be aliased with the tsunami signal. The filter is applied to 1-min observations, with missing data filled using cubic-spline interpolation.

Figure 13 shows that sea level fluctuations in the open ocean during this event were underestimated by $\mathrm{T} 2$. It is worth considering the implications of this. An objective (or subjective) data assimilation scheme, for example, might increase the $\mathrm{T} 2$ amplitude values by a factor of up to 3 , in order to match the observations in Fig. 13. This may trigger warnings in the coastal zones, if the threshold level is reached. However, inspection of Fig. 8 shows that the 95th percentile value for any coastal zone for this event is less than $5 \mathrm{~cm}$, so even if the scaling factor mentioned above was applied, the threshold value of $20 \mathrm{~cm}$ would still not be reached and warnings would still not be warranted.

\section{Land threat threshold}

As mentioned in Sect. 3, none of the case studies examined here exhibited inundation significant enough to warrant a land threat warning. Given this, the land threat thresholds were set just above the highest marine warning values in Fig. 8. In order to verify this, an event with significant inundation would need to be examined. The Sumatra 2004 event is the obvious candidate for this and although it did not produce inundation on the Australian coastline, the impacts on other countries within the Indian Ocean are well documented. In this section, we assess whether the land threat threshold is appropriate by applying the warnings method to the Sumatra 2004 event using an extended set of coastal zones that have been drafted for potential use with the Indian Ocean Tsunami Warning System (IOTWS). This extended set of zones is comprised of the Australian coastal zones used elsewhere in this study and an additional series of zones covering the coastal waters and islands of the Indian Ocean.
There are some differences between the Australian and Indian Ocean zones. For example, while the Indian Ocean zones span similar distances along the coastline, they are considerably narrower than the Australian zones in terms of distance from the coastline. Perhaps more significantly, the coastal boundary of the Indian Ocean zones does not extend fully to the coastline, which presents an inconsistency with the Australian zones. This means that this extended set of zones can only be of limited use, however given the absence of any other spatial definitions, this currently provides the best available information.

The derived warning scheme for the Sumatra event using the extended set of coastal zones and the thresholds listed in Sect. 3.2 is shown in Fig. 14. Kong and Synolakis (2006) provide an extensive and detailed summary of impacts for this event by means of a compilation of runup measurements from other studies. Comparing Fig. 14 to the impacts described in that study suggests that the choice of thresholds appears to be appropriate, at least for this event. Land threats are predicted in most areas where significant impacts occured. The warning method does underestimate the impacts in parts of the Seychelles archipelagos, the south west coast of India and parts of Madagascar. Contrastingly, there are some land and marine threats issued for areas where a lower level of impacts was observed, e.g. parts of Somalia and the north west coast of India. Despite these variations, the application of the recommended thresholds to T2 produces a warning scheme that matches the observed impacts very well. This provides some validation of the recommended thresholds in Sect. 3.2.

\section{Discussion}

This study has described an enhanced method for generating coastal tsunami warnings from model data obtained from the $\mathrm{T} 2$ scenario database. It is based on the method introduced in AG08, but incorporates some significant enhancements.

One major change from AG08 is that the 95th percentile value of $H_{\max }$ within a coastal zone is compared against empirically determined thresholds. This differs from the approach in AG08, where the largest $H_{\max }$ in each coastal zone was used. The present approach is aimed at providing a more robust method for assessing the warning levels.

Another difference from AG08 is the manner in which thresholds were chosen. For the present method, warning schemes were carefully developed for past tsunami events, based on a retrospective knowledge of impacts following each event. Thresholds were then chosen to produce warning schemes that best matched these hindcasts. This subtle but important difference from AG08 results in a scheme more closely tied to impacts. In other words, the observed impacts are used in this study to explicitly design the warnings method, rather than to verify it, as in AG08. 

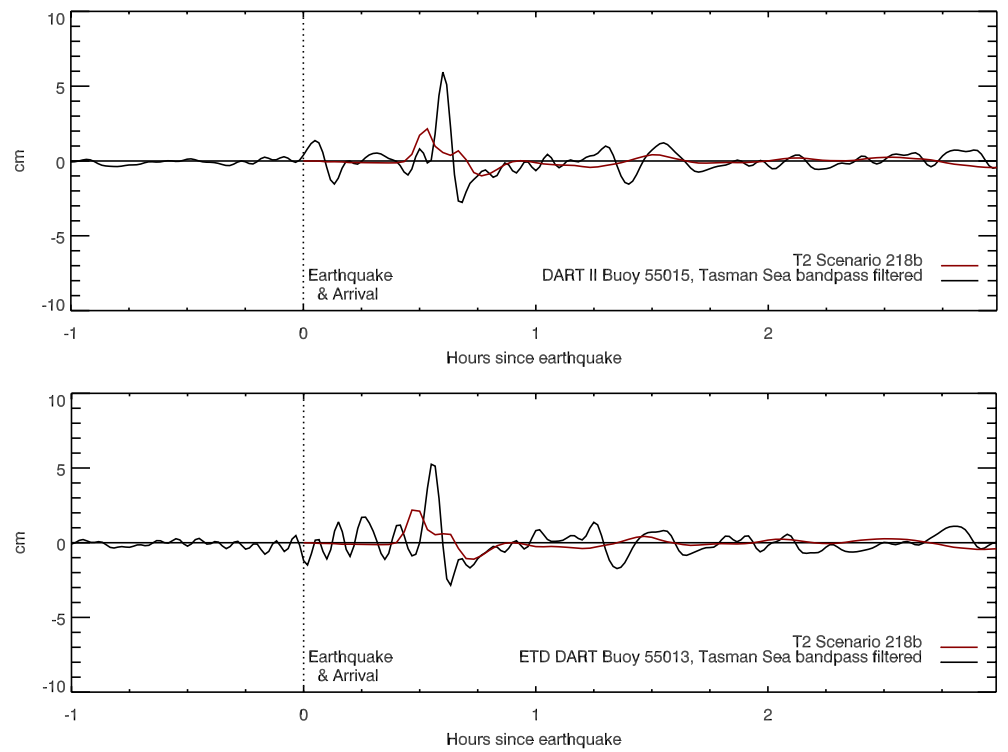

Fig. 13. Comparison of nearest T2 scenario for the Puysegur 2009 event with observations from Tsunameters 55015 (top) and 55013 (bottom), situated in the Tasman Sea. A description of how the tsunameter observations have been processed is in the text.

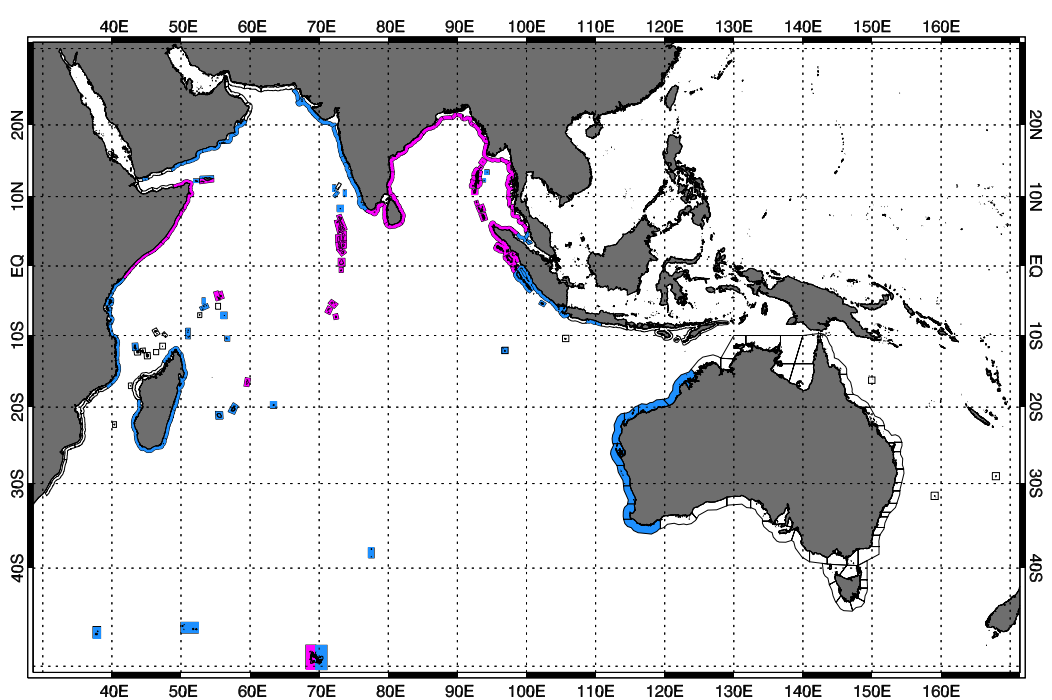

Fig. 14. Derived T2 warnings for the Sumatra 2004 event using the extended set of Indian Ocean coastal zones and the thresholds in Sect. 3.2. Coastal zones assigned marine and land threats are shaded in blue and magenta, respectively.

Although tsunami events in the Australian region are rare and very few have had any significant documented impact on the Australian coastline, the suite of events available for a study of this nature will expand over time. This will allow further confirmation or refinement of the method and thresholds devised here. Given that this method is entirely empirical in nature and impact-based, this ongoing analysis and potential refinement is important and worthwhile.

One limitation to this method is that the coastal zones have varying shapes, sizes and bathymetric details. An alternate scheme might employ unique warning thresholds for each coastal zone. However the limited number of past tsunami events clearly prohibits this. Many zones have never required a marine warning, so there is no guidance as to where to place this threshold for those zones, let alone the land threat threshold. Another extension related to developing individual thresholds for each zone is to design new coastal zones. In particular, the coastal morphology of the zones, and its potential effects on incoming tsunamis, could be taken into account by designing the zones so that they extend to, say, the same depth offshore, rather than to the same distance.

In real time, the estimates of an earthquake's location and magnitude can change rapidly over time as more seismic data is observed. This can result in signifcant variations and 
errors in tsunami forecasts and any subsequent warnings. The assimilation of actual tsunami observations by way of tsunameter data would greatly reduce these errors. Research efforts toward an assimilation scheme for use with the T2 scenario database is an area of active research.

Implementation of the MOST model used in the T2 tsunami scenario database is not designed to accurately simulate tsunamis in complex, shallow bathymetry, such as near the coastline. The method employed here highlights this limitation at times, for example as seen in the Java 2006 and Sumatra 2005 events. It should be remembered that the most accurate means of evaluating the impact of tsunamis on coastlines is to use inundation modelling. Since the overwhelming computational and bathymetric data requirements of inundation modelling currently make this approach infeasible for the long Australian coastline in a real-time system, the method devised here allows $\mathrm{T} 2$ to be used as a proxy for impacts at the coastline.

Acknowledgements. The authors thank Arthur Simanjuntak, Tony Leggett, Chris Ryan, Geoff Crane and William Power for useful discussions regarding the method and Paul Whitmore and an anonymous reviewer for their useful and constructive reviews.

Edited by: S. Monserrat

Reviewed by: P. Whitmore and another anonymous referee

\section{References}

Allen, S. C. R. and Greenslade, D. J. M.: Developing tsunami warnings from numerical model output, Nat. Hazards, 46, 3552, doi:10.1107/s11069000791808, 2008.

Allen, S. C. R. and Greenslade, D. J. M.: A spectral climatology of Australian and South West Pacific tide gauges, Bureau of Meteorology, Melbourne, Australia, CAWCR Technical Report No. 011, 52 pp., 2009.

Ammon, C. J., Kanamori, H., Lay, T., and Velasco, A. A.: The 17 July 2006 Java tsunami earthquake, Geophys. Res. Lett., 33, L24308, doi:10.1029/2006GL028005, 2006.

Bathgate, J. S., Volti, T., and Greenslade, D. J. M.: The Joint Australian Tsunami Warning Centre: responding to a tsunamigenic earthquake - Puysegur Trench, 30 September 2007, Preview, 133, 40-44, 2008.

Bureau of Meteorology: BoM - Oceanographic Services: Australian Baseline Sea Level Monitoring Project, available at: http://www.bom.gov.au/oceanography/projects/abslmp/ abslmp.shtml (last access: 21 October 2010), 2010.

Dominey-Howes, D.: Geological and historical records of tsunami in Australia, Mar. Geol., 239, 99-123, 2007.

Gica, E., Spillane, M., Titov, V. V., Chamberlin, C., and Newman, J. C.: Development of the forecast propagation database for NOAA's Short-term Inundation Forecast for Tsunamis (SIFT), NOAA Tech. Memo. OAR PMEL-139, 89 pp., 2008.

Greenslade, D. J. M. and Titov, V. V.: A Comparison Study of Two Numerical Tsunami Forecasting Systems, Pure Appl. Geophys., 165, 1991-2001, doi:10.1007/978-3-0346-0057-6_2, 2009.
Greenslade, D. J. M., Simanjuntak, M. A., Burbidge, D., and Chittleborough, J.: A first-generation real-time tsunami forecasting system for the Australian Region, Bureau of Meteorology, Melbourne, Australia, BMRC Research Report No. 126, 75 pp., 2007.

Greenslade, D. J. M., Simanjuntak, M. A., and Allen, S. C. R.: An enhanced tsunami scenario database: T2, Bureau of Meteorology, Melbourne, Australia, CAWCR Technical Report No. 014, 30 pp., 2009.

Greenslade, D. J. M., Allen, S. C. R., and Simanjutank, M. A.: An Evaluation of Tsunami Forecasts from the T2 Scenario Database, Pure Appl. Geophys. Topical Volume, in press, doi:10.1007/s00024-010-0229-3, 2010.

Kong, L. and Synolakis, C. E.: Runup Measurements of the December 2004 Indian Ocean Tsunami, Earthq. Spectra, 22(S3), S67-S91, 2006.

Mei, C. C., Stiassnie, M., and Yue, D. K.-P.: Theory and Applications of Ocean Surface Waves. Part 1: Linear Aspects, World Scientific, Singapore, 506 pp., 2005.

National Meteorological and Oceanographic Centre (NMOC), Australian Tsunami Warning System Standard Operating Procedures, Version 3.6B, Bureau of Meteorology, 2010.

Northwest Telegraph: Lucky escape for Camper, 5 January 2005.

Plafker, G.: Alaskan earthquake of 1964 and Chilean earthquake of 1960: Implications for arc tectonics, J. Geophys. Res., 77(5), 901-925, 1972.

Prendergast, A.: The Impact of the 2006 Java Tsunami on the Australian Coast: Post-tsunami Survey at Steep Point, Western Australia, AGU Fall meeting, San Francisco, USA, December, abstract \#OS43C-0669, 2006.

Rabinovich, A. B. and Thomson, R. E.: The 26 December 2004 Sumatra tsunami: Analysis of tide gauge data from the World Ocean. Part 1. Indian Ocean and South Africa, Pure Appl. Geophys., 164, 261-308, 2007.

Simanjuntak, M. A. and Greenslade, D. J. M.: Magnitude-based Scaling of Tsunami Propagation, J. Geophys. Res.-Oceans, submitted, 2010.

Tang, L., Titov, V. V., Wei, Y., Mofjeld, H. O., Spillane, M., Arcas, D., Bernard, E. N., Chamberlin, C., Gica, E., and Newman, J.: Tsunami forecast analysis for the May 2006 Tonga tsunami, J. Geophys. Res., 113, C12015, doi:10.1029/2008JC004922, 2008.

The Age: Pacific tsunami carnage: Dozens die, panic in Australia after quake strikes Solomons, 3 April 2007.

Titov, V. V. and Synolakis, C. E.: Numerical Modeling of Tidal Wave Runup, J. Waterw. Port C. Div., 124(4), 157-171, 1998.

USGS: Historic World Earthquakes, available at: http://earthquake. usgs.gov/regional/world/historical.php (last access: 6 September 2010), 2010a.

USGS: Magnitude 8.6 - Northern Sumatra, Indonesia, 2005 March 28 16:09:36 UTC, available at: http://earthquake.usgs.gov/ earthquakes/eqinthenews/2005/usweax/usweax.php (last access: 6 September 2010), 2010b.

Uslu, B., Power, W., Greenslade, D., Eblé, M., and Titov, V.: The July 15, 2009 Fiordland, New Zealand tsunami: real-time assessment, Pure Appl. Geophys., accepted, 2010.

Whitmore, P. M.: Tsunami amplitude prediction during events: a test based on previous tsunamis, Sci. Tsunami Haz. 21, 135-143, 2003. 